\title{
Exercise in Patients with Heart Failure
}

\author{
Christine J. Chung and P. Christian Schulze \\ Division of Cardiology, Department of Medicine, Columbia University Medical Center, New York, \\ NY 10032, USA
}

\begin{abstract}
For the patient with heart failure, dyspnea and fatigue resulting in diminished exercise tolerance are among the main factors contributing to decreased social and physical functioning and quality of life. There has long been evidence that measures of cardiac function such as ejection fraction and cardiac output only poorly correlate with a patient's capacity to exercise, suggesting the involvement of factors other than those impacting the central circulation. The lack of a close correlation between central hemodynamics and exercise tolerance has led to investigations into alterations in the periphery, such as abnormalities in vascular endothelial function, hyperactivation of the sympathetic nervous system, and changes in structure and oxidative capacity of skeletal muscle, which are commonly seen in patients with heart failure. Over the past two decades, numerous clinical studies have demonstrated the beneficial impact of exercise training on skeletal muscle energy metabolism, vascular function, and ventilatory capacity, which correlate with measures of exercise tolerance, improvements in hospitalization rates and quality of life of patients with heart failure. In accordance with recent guidelines set forth by the leading cardiology societies in the United States and Europe, physicians are urged to emphasize exercise training for all clinically stable patients with heart failure using individualized protocols that feature early mobilization after acute exacerbations of disease and gradual increases in intensity.
\end{abstract}

\section{Keywords}

Heart failure; skeletal muscle; vascular function; exercise capacity; exercise training

\section{INTRODUCTION}

Heart failure is a prevalent disease affecting approximately five million Americans and 10\% or more of those aged 70 years and older. ${ }^{1,2}$ Despite significant advances in therapy, heart failure remains a significant cause of hospital admissions and patients who are symptomatic have a one-year mortality rate approaching $45 \% .^{2}$ For the patient, dyspnea and fatigue resulting in diminished exercise tolerance are among the main factors contributing to decreased social and physical functioning and quality of life. ${ }^{3}$ There has long been evidence that measures of cardiac function such as ejection fraction and cardiac output only poorly correlate with a patient's capacity to exercise, suggesting the involvement of factors other than those impacting the central circulation. Furthermore, many studies of the effects of exercise in patients with heart failure have failed to demonstrate improvements in cardiac output, stroke volume, or ejection fraction, despite showing gains in exercise capacity and peak oxygen uptake $\left(\mathrm{VO}_{2}\right){ }_{5}^{4}$ which has been validated as an excellent isolated predictor of outcome in this population ${ }^{5}$. The lack of a close correlation between central hemodynamics 
and exercise tolerance has led to investigations into alterations in the periphery, such as abnormalities in vascular endothelial function, hyperactivation of the sympathetic nervous system, and changes in structure and oxidative capacity of skeletal muscle, which are often seen in patients with heart failure.

\section{PERIPHERAL FACTORS THAT DETERMINE EXERCISE CAPACITY IN HEART FAILURE \\ MUSCLE}

The myopathy associated with heart failure affects both cardiac and skeletal muscle, and encompasses alterations in structure and function. Mitochondrial oxidative capacity is impaired due to decreased oxidative enzyme activity, mitochondrial volume density and biogenesis, as well as increased reliance upon glucose rather than fatty acid oxidation. There is a shift from fatigue-resistant type I fibers that primarily rely on mitochondrial oxidative phosphorylation to generate ATP to type II fibers that have a higher glycogen content and derive most of their energy from glycolysis. Additionally, skeletal muscle in heart failure patients has decreased capillary density ${ }^{6}$, which correlates with maximal $\mathrm{VO}_{2}$ and total exercise time ${ }^{7}$. Fiber atrophy and decreased muscle mass also occur, and have been demonstrated to account for much of the variability in peak $\mathrm{VO}_{2}{ }^{8}$

In an effort to determine the link between changes in muscle mass, strength, fiber type, and parameters of exercise capacity, Vescovo et al. showed that heart failure patients with low peak $\mathrm{VO}_{2}$ and high fatigability have increased myocyte apoptosis. Fiber cross-sectional area and prevalence of apoptosis were found to correlate with reduction in peak $\mathrm{VO}_{2}$ and endurance during repetitive exercise. ${ }^{9}$ Further, skeletal muscle wasting has been attributed in part to the elevated levels of angiotensin II known to occur in heart failure, which reduce appetite and enhance catabolism. Tabony et al. infused mice with angiotensin II and found they had a significant additional decrease in skeletal muscle mass when controlling for decreased caloric intake. ${ }^{10}$

\section{VASCULATURE}

The endothelium plays an important role in regulating vascular tone, and abnormalities in vascular endothelial function shown to occur in heart failure patients are associated with a generalized reduced vasodilatory capacity and increased mortality risk. ${ }^{11-13}$ Endotheliumderived nitric oxide-mediated vasodilation is decreased in the peripheral, coronary, and pulmonary circulations of patients with HF. ${ }^{14-16}$ The inability of the peripheral vasculature to respond physiologically to variations in cardiac output, peripheral blood flow and positional changes results in increased peripheral vascular resistance and imbalance in blood pressure regulation in patients with advanced heart failure. The underlying mechanisms are still unclear. Endothelial cell apoptosis ${ }^{17}$ and increased oxidative stress ${ }^{18}$, as well as the impact of reduced cardiac output and lower blood pressure waveforms, have been suggested to contribute to this phenomenon.

\section{VENTILATORY SYSTEM}

Patients with heart failure are known to have exaggerated increases in minute ventilation during exercise disproportionate to the increase in carbon dioxide production ${ }^{19}$, and this has been associated with poor prognosis for patients with moderate to severe heart failure ${ }^{20}$. Even in those patients with preserved exercise tolerance, abnormal enhancement of the ventilatory response to exercise indicates dysregulation of the cardiorespiratory reflex and independently predicts increased mortality. ${ }^{20}$ Elevated pulmonary pressures, ventilation/ perfusion mismatch, earlier onset of metabolic acidosis, dysregulation of reflex control, deconditioning, and an abnormal pattern of rapid, shallow respirations have been proposed 
mechanisms for the exaggerated ventilatory response to exercise in patients with heart failure. $^{21}$

Several studies have also established the presence of inspiratory muscle weakness, which is likely a manifestation of global skeletal muscle myopathy. A prospective study of nearly 250 patients showed that degree of respiratory muscle weakness is related to the severity of heart failure, as evidenced by a correlation between maximum inspiratory pressure $\left(\mathrm{Pi}_{\max }\right)$ and New York Heart Association (NYHA) class. Furthermore, there was a striking difference in survival between the lowest quartile of $\mathrm{Pi}_{\max }$ (approximately 50\%) and the highest quartile $(15 \%)$ over the 3 -year follow-up period. ${ }^{22}$

\section{EFFECTS OF EXERCISE ON PERIPHERAL DERANGEMENTS IN HEART FAILURE MUSCLE}

There is significant evidence of a link between the enhancement of peak oxygen uptake and exercise capacity seen after training and correction of skeletal muscle derangements in patients with heart failure. Several small studies conducted in the 1990s demonstrated correlations between improved parameters of exercise tolerance and amelioration of some of the changes thought responsible for reduced oxidative capacity of skeletal muscle. ${ }^{23-25}$ Exercise training was shown to induce increased mitochondrial volume density as well as a shift from type II back to type I fibers. ${ }^{26}$ More recently, Williams et al. conducted a small randomized controlled trial to study the impact of resistance training on skeletal muscle mitochondrial ATP production rate, metabolic enzyme activity and capillary density and found significant improvements with training compared to usual care alone. Furthermore, these changes in the oxidative capacity of skeletal muscle correlated with improvements in peak $\mathrm{VO}_{2}{ }^{27}$

Insulin resistance, which is commonly seen even in nondiabetic patients with heart failure, has also been associated with reduced exercise capacity. ${ }^{28}$. One proposed explanation for the prevalence of insulin resistance has been functional resistance to adiponectin, an insulinsensitizing adipocytokine. Van Berendoncks et al. studied heart failure patients who underwent 4 months of combined endurance and resistance exercise training and found, at baseline, a negative correlation between levels of adiponectin mRNA in skeletal muscle and $\mathrm{VO}_{2}$ peak and muscle strength, as well as a positive correlation between measures of exercise capacity and mRNA expression of the skeletal muscle receptor for adiponectin, AdipoR1, and the downstream signaling molecules AMPK- $\alpha 1$ subunit and PPAR- $\alpha$, all suggesting a link between functional adiponectin resistance and decreased exercise capacity. After exercise training, adiponectin mRNA in skeletal muscle decreased by $67 \%$ and mRNA expression of AdipoR1, PPAR- $\alpha$, and AMPK all increased significantly, approaching normal levels. ${ }^{29}$ By improving skeletal muscle responsiveness to adiponectin, exercise training may increase insulin sensitivity in patients with heart failure.

\section{VASCULATURE}

A significant amount of research on the mechanisms responsible for the decreased cardiovascular risk associated with exercise training has focused on its direct effects on the microstructure of the peripheral vasculature. A prospective cohort study of 16 patients participating in a 3-month exercise training program (aerobic exercise with or without strength training) found that oxygen reperfusion rate and vascular reactivity following the release of vascular occlusion, both indirect indices of endothelial function, increased significantly after exercise training. The study authors postulated that improved peripheral circulation seen after exercise training could be due to improved peripheral vascular 
resistance, anti-inflammatory effects of exercise, and attenuation of neuroendocrine activation. 30

Maiorana et al. found that identical exercise regimens corrected endothelial dysfunction and induced improvement in nitric oxide-mediated acetylcholine-induced vasodilator function in subjects with heart failure and type II diabetes mellitus ${ }^{31}$, but not in asymptomatic agematched controls ${ }^{32}$, which suggests that it may be difficult to enhance function above a "normal" level in healthy persons. Nevertheless, the changes in shear stress associated with acute exercise are a potent stimulus of vasodilator adaptation in patients with heart failure.

Animal studies have shown that exercise training leads to changes in the elastin, collagen, and smooth muscle content in the aortic wall. The thoracic aorta, which has a higher elastin/ collagen ratio than distal arteries, has an important role in dampening pressure oscillations and thus minimizing pulsatility. In both human and animal models, hypertension has been associated with microstructural remodeling and mechanical changes in the aorta, contributing to increased wall stiffness and transmission of pressure oscillations which have been associated with end organ damage. Animal studies have demonstrated that aerobic exercise training reversed altered vascular structure and normalized the wall/lumen ratio of the arteriole. ${ }^{33}$

\section{VENTILATORY SYSTEM}

In a small randomized controlled trial, Myers et al. demonstrated that 2 months of aerobic endurance training led to improved ventilatory response, increased efficiency of ventilation, reduced lactate levels in the blood throughout exercise, and delayed lactate threshold, factors all known to impact exercise capacity. ${ }^{21}$ Additionally, Guazzi et al. found that patients with heart failure have impaired gas-diffusion across the alveolar capillary membrane that improved after exercise training. Increased diffusion capacity and conductance of the alveolar capillaries correlated with improvement in peak $\mathrm{VO}_{2}$ after 8 weeks of aerobic endurance exercise. ${ }^{34}$

Targeted training of the diaphragm and other muscles of respiration, either alone or as an adjunct to global exercise training, also leads to improvements in ventilatory function, as evidenced by increased $\mathrm{Pi}_{\max }$ and peak circulatory power, as well as in exercise capacity, demonstrated by enhanced peak $\mathrm{VO}_{2}$ and oxygen uptake efficiency slope. Furthermore, inspiratory muscle training has been shown to improve patients' quality of life and functional status. ${ }^{35}$ Most studies that have demonstrated the benefits of inspiratory muscle training have been conducted in patients with inspiratory muscle weakness $\left(\mathrm{PI}_{\max }<70 \%\right.$ of predicted) at baseline.

\section{EXERCISE AS A NON-PHARMACOLOGIC INTERVENTION IN HEART FAILURE DIFFERENT MODALITIES OF EXERCISE}

There are three main types of exercise training programs: 1) aerobic endurance (continuous or interval), 2) strength/resistance, and 3) respiratory. In particular, several groups have studied the impact of incorporating strength/resistance training into the more traditionally prescribed endurance training regimens. A randomized study of nearly 60 heart failure patients assigned to either endurance training alone or combined training demonstrated that maximal exercise capacity and work-economy increased significantly more in the combined group. ${ }^{36}$ Similarly, Anagnostakou et al. randomized heart failure patients to interval cycle training alone or a combined program including strength training of targeted large muscle groups and found that although peak oxygen uptake increased in both groups, a significant 
improvement in flow-mediated arterial dilation occurred only in the combined group. ${ }^{12}$ These and similar studies suggest that resistance training may confer additional, perhaps unique, improvements in muscle strength and endurance, as well as vascular reactivity and favorable remodeling of conduit arteries. ${ }^{37}$

\section{HF-ACTION TRIAL}

To date, there has only been one large, multi-center, randomized controlled trial to investigate the effect of adding exercise training to optimized medical treatment on mortality, hospitalizations, and patients' self-reported health status and quality of life. Data from Heart Failure: A Controlled Trial Investigating Outcomes of Exercise Training (HFACTION) showed that exercise training led to reductions in all-cause mortality and hospitalizations that reached a modest level of significance after adjustment for highly prognostic baseline characteristics such as duration of the cardiopulmonary exercise test and history of atrial fibrillation or flutter..$^{38,39}$

Despite previous smaller studies which suggested positive effects of exercise training on physical function, quality of life, biomarkers and even survival and hospitalizations, there was lingering concern about safety. Though the American College of Cardiology and the American Heart Association recommend that physical activity be considered for medically stable patients with systolic dysfunction, the lack of strong evidence from adequately powered studies likely prevented widespread adoption of this practice. ${ }^{38}$ HF-ACTION was important in establishing the safety of exercise training in patients with NYHA II-IV heart failure showing comparable event rates in both groups but reduced hospitalizations and better quality-of-life in the exercise arm of the trial. ${ }^{39}$

Investigation of the impact of exercise training on patients with heart failure is ongoing following the results of HF-ACTION. Recently, Nishi et al. examined the efficacy and safety of exercise training in patients with advanced heart failure on $\beta$-blocker therapy who all had a left ventricular ejection fraction less than $25 \%$, compared to those enrolled in HFACTION in which half of the patients had an ejection fraction greater than $25 \%$, and found a significant increase in peak $\mathrm{VO}_{2}$, peak work rate, and decreased plasma BNP levels solely in the group that underwent exercise training. ${ }^{40}$ One patient (3\%) in the exercise training group experienced worsening of heart failure during the study, and there were no serious cardiac events such as death or cardiopulmonary arrest.

\section{CURRENT RECOMMENDATIONS FOR EXERCISE IN HEART FAILURE}

In 2009, the American College of Cardiology and the American Heart Association established updated guidelines for the diagnosis and management of heart failure and recommended that exercise training be prescribed in conjunction with drug therapy for all stable outpatients. ${ }^{41}$ Likewise, in 2008, the European Society of Cardiology firmly recommended regular physical activity and structured exercise training for patients with heart failure. ${ }^{42}$

A consensus document of the European Association for Cardiovascular Prevention and Rehabilitation and the Heart Failure Association provides practical guidelines for implementation. Stable patients with NYHA class I-III heart failure should undergo exercise training using individualized protocols that begin with gradual mobilization, initially done without weights or equipment. Early mobilization after hospitalizations for acute exacerbations is recommended. ${ }^{43}$

Both endurance and strength/resistance training have been shown to improve exercise time and peak $\mathrm{VO}_{2}$, as well as submaximal exercise capacity as assessed by the 6-min walking 
test. Patients, particularly those with inspiratory muscle weakness, may derive additional benefit from respiratory muscle training. Physicians are encouraged to take into account the patient's preferences, abilities, and access to equipment and facilities when prescribing an exercise training program. However, patients over the age of 65 years accustomed to a sedentary lifestyle should utilize modalities other than resistance/strength training until they are better conditioned $\left(\mathrm{VO}_{2}\right.$ peak $>18 \mathrm{ml} / \mathrm{kg} / \mathrm{min}$ or $>450 \mathrm{~m}$ on 6 -min walking test) ${ }^{43}$

In conclusion, exercise training is a safe non-pharmacological intervention in clinically stable patients with heart failure on standard medical therapy with positive effects on both morbidity and quality of life.

\section{References}

1. McMurray JJ. Clinical practice. Systolic heart failure. N Engl J Med. Jan 21; 2010 362(3):228-238. [PubMed: 20089973]

2. Jessup M, Brozena S. Heart failure. N Engl J Med. May 15; 2003 348(20):2007-2018. [PubMed: 12748317]

3. Downing J, Balady GJ. The role of exercise training in heart failure. J Am Coll Cardiol. Aug 2; 2011 58(6):561-569. [PubMed: 21798416]

4. Belardinelli R, Georgiou D, Scocco V, Barstow TJ, Purcaro A. Low intensity exercise training in patients with chronic heart failure. J Am Coll Cardiol. Oct; 1995 26(4):975-982. [PubMed: 7560627]

5. Mancini D, LeJemtel T, Aaronson K. Peak VO(2): a simple yet enduring standard. Circulation. Mar 14; 2000 101(10):1080-1082. [PubMed: 10715250]

6. Drexler H, Riede U, Munzel T, Konig H, Funke E, Just H. Alterations of skeletal muscle in chronic heart failure. Circulation. May; 1992 85(5):1751-1759. [PubMed: 1315220]

7. Duscha BD, Kraus WE, Keteyian SJ, et al. Capillary density of skeletal muscle: a contributing mechanism for exercise intolerance in class II-III chronic heart failure independent of other peripheral alterations. J Am Coll Cardiol. Jun; 1999 33(7):1956-1963. [PubMed: 10362199]

8. Volterrani M, Clark AL, Ludman PF, et al. Predictors of exercise capacity in chronic heart failure. European heart journal. Jun; 1994 15(6):801-809. [PubMed: 8088269]

9. Vescovo G, Volterrani M, Zennaro R, et al. Apoptosis in the skeletal muscle of patients with heart failure: investigation of clinical and biochemical changes. Heart. Oct; 2000 84(4):431-437. [PubMed: 10995417]

10. Tabony AM, Yoshida T, Galvez S, et al. Angiotensin II Upregulates Protein Phosphatase 2C $\{$ alpha $\}$ and Inhibits AMP-Activated Protein Kinase Signaling and Energy Balance Leading to Skeletal Muscle Wasting. Hypertension. Aug 15.2011

11. Katz SD, Hryniewicz K, Hriljac I, et al. Vascular endothelial dysfunction and mortality risk in patients with chronic heart failure. Circulation. Jan 25; 2005 111(3):310-314. [PubMed: 15655134]

12. Anagnostakou V, Chatzimichail K, Dimopoulos S, et al. Effects of interval cycle training with or without strength training on vascular reactivity in heart failure patients. Journal of cardiac failure. Jul; 2011 17(7):585-591. [PubMed: 21703531]

13. Fischer D, Rossa S, Landmesser U, et al. Endothelial dysfunction in patients with chronic heart failure is independently associated with increased incidence of hospitalization, cardiac transplantation, or death. European heart journal. Jan; 2005 26(1):65-69. [PubMed: 15615801]

14. Ramsey MW, Goodfellow J, Jones CJ, Luddington LA, Lewis MJ, Henderson AH. Endothelial control of arterial distensibility is impaired in chronic heart failure. Circulation. Dec 1; 1995 92(11):3212-3219. [PubMed: 7586306]

15. Porter TR, Taylor DO, Cycan A, et al. Endothelium-dependent pulmonary artery responses in chronic heart failure: influence of pulmonary hypertension. J Am Coll Cardiol. Nov 1; 1993 22(5): 1418-1424. [PubMed: 8227800] 
16. Treasure CB, Vita JA, Cox DA, et al. Endothelium-dependent dilation of the coronary microvasculature is impaired in dilated cardiomyopathy. Circulation. Mar; 1990 81(3):772-779. [PubMed: 2306829]

17. Rossig L, Haendeler J, Mallat Z, et al. Congestive heart failure induces endothelial cell apoptosis: protective role of carvedilol. J Am Coll Cardiol. Dec; 2000 36(7):2081-2089. [PubMed: 11127444]

18. Dworakowski R, Walker S, Momin A, et al. Reduced nicotinamide adenine dinucleotide phosphate oxidase-derived superoxide and vascular endothelial dysfunction in human heart failure. J Am Coll Cardiol. Apr 8; 2008 51(14):1349-1356. [PubMed: 18387435]

19. Sullivan MJ, Higginbotham MB, Cobb FR. Increased exercise ventilation in patients with chronic heart failure: intact ventilatory control despite hemodynamic and pulmonary abnormalities. Circulation. Mar; 1988 77(3):552-559. [PubMed: 3342486]

20. Ponikowski P, Francis DP, Piepoli MF, et al. Enhanced ventilatory response to exercise in patients with chronic heart failure and preserved exercise tolerance: marker of abnormal cardiorespiratory reflex control and predictor of poor prognosis. Circulation. Feb 20; 2001 103(7):967-972. [PubMed: 11181471]

21. Myers J, Dziekan G, Goebbels U, Dubach P. Influence of high-intensity exercise training on the ventilatory response to exercise in patients with reduced ventricular function. Medicine and science in sports and exercise. Jul; 1999 31(7):929-937. [PubMed: 10416552]

22. Meyer FJ, Borst MM, Zugck C, et al. Respiratory muscle dysfunction in congestive heart failure: clinical correlation and prognostic significance. Circulation. May 1; 2001 103(17):2153-2158. [PubMed: 11331255]

23. Adamopoulos S, Coats AJ, Brunotte F, et al. Physical training improves skeletal muscle metabolism in patients with chronic heart failure. J Am Coll Cardiol. Apr; 1993 21(5):1101-1106. [PubMed: 8459063]

24. Stratton JR, Dunn JF, Adamopoulos S, Kemp GJ, Coats AJ, Rajagopalan B. Training partially reverses skeletal muscle metabolic abnormalities during exercise in heart failure. J Appl Physiol. Apr; 1994 76(4):1575-1582. [PubMed: 8045834]

25. Hambrecht R, Niebauer J, Fiehn E, et al. Physical training in patients with stable chronic heart failure: effects on cardiorespiratory fitness and ultrastructural abnormalities of leg muscles. J Am Coll Cardiol. May; 1995 25(6):1239-1249. [PubMed: 7722116]

26. Hambrecht R, Fiehn E, Yu J, et al. Effects of endurance training on mitochondrial ultrastructure and fiber type distribution in skeletal muscle of patients with stable chronic heart failure. $\mathrm{J} \mathrm{Am}$ Coll Cardiol. Apr; 1997 29(5):1067-1073. [PubMed: 9120161]

27. Williams AD, Carey MF, Selig S, et al. Circuit resistance training in chronic heart failure improves skeletal muscle mitochondrial ATP production rate--a randomized controlled trial. Journal of cardiac failure. Mar; 2007 13(2):79-85. [PubMed: 17395046]

28. AlZadjali MA, Godfrey V, Khan F, et al. Insulin resistance is highly prevalent and is associated with reduced exercise tolerance in nondiabetic patients with heart failure. J Am Coll Cardiol. Mar 3; 2009 53(9):747-753. [PubMed: 19245964]

29. Van Berendoncks AM, Garnier A, Beckers P, et al. Exercise training reverses adiponectin resistance in skeletal muscle of patients with chronic heart failure. Heart. Sep; 2011 97(17):14031409. [PubMed: 21685184]

30. Gerovasili V, Drakos S, Kravari M, et al. Physical exercise improves the peripheral microcirculation of patients with chronic heart failure. Journal of cardiopulmonary rehabilitation and prevention. Nov-Dec;2009 29(6):385-391. [PubMed: 19770806]

31. Maiorana A, O'Driscoll G, Cheetham C, et al. The effect of combined aerobic and resistance exercise training on vascular function in type 2 diabetes. J Am Coll Cardiol. Sep; 2001 38(3):860 866. [PubMed: 11527646]

32. Maiorana A, O'Driscoll G, Dembo L, Goodman C, Taylor R, Green D. Exercise training, vascular function, and functional capacity in middle-aged subjects. Medicine and science in sports and exercise. Dec; 2001 33(12):2022-2028. [PubMed: 11740294] 
33. Jordao MT, Ladd FV, Coppi AA, Chopard RP, Michelini LC. Exercise Training Restores Hypertension-Induced Changes in the Elastic Tissue of the Thoracic Aorta. Journal of vascular research. Aug 10; 2011 48(6):513-524. [PubMed: 21829037]

34. Guazzi M, Reina G, Tumminello G, Guazzi MD. Improvement of alveolar-capillary membrane diffusing capacity with exercise training in chronic heart failure. J Appl Physiol. Nov; 2004 97(5): 1866-1873. [PubMed: 15220300]

35. Dall'Ago P, Chiappa GR, Guths H, Stein R, Ribeiro JP. Inspiratory muscle training in patients with heart failure and inspiratory muscle weakness: a randomized trial. J Am Coll Cardiol. Feb 21; 2006 47(4):757-763. [PubMed: 16487841]

36. Beckers PJ, Denollet J, Possemiers NM, Wuyts FL, Vrints CJ, Conraads VM. Combined endurance-resistance training vs. endurance training in patients with chronic heart failure: a prospective randomized study. European heart journal. Aug; 2008 29(15):1858-1866. [PubMed: 18515805]

37. Maiorana AJ, Naylor LH, Exterkate A, et al. The impact of exercise training on conduit artery wall thickness and remodeling in chronic heart failure patients. Hypertension. Jan; 2011 57(1):56-62. [PubMed: 21059991]

38. Flynn KE, Pina IL, Whellan DJ, et al. Effects of exercise training on health status in patients with chronic heart failure: HF-ACTION randomized controlled trial. JAMA : the journal of the American Medical Association. Apr 8; 2009 301(14):1451-1459. [PubMed: 19351942]

39. O'Connor CM, Whellan DJ, Lee KL, et al. Efficacy and safety of exercise training in patients with chronic heart failure: HF-ACTION randomized controlled trial. JAMA : the journal of the American Medical Association. Apr 8; 2009 301(14):1439-1450. [PubMed: 19351941]

40. Nishi I, Noguchi T, Iwanaga Y, et al. Effects of exercise training in patients with chronic heart failure and advanced left ventricular systolic dysfunction receiving beta-blockers. Circulation journal : official journal of the Japanese Circulation Society. Jun 24; 2011 75(7):1649-1655. [PubMed: 21613745]

41. Hunt SA, Abraham WT, Chin MH, et al. 2009 Focused update incorporated into the ACC/AHA 2005 Guidelines for the Diagnosis and Management of Heart Failure in Adults A Report of the American College of Cardiology Foundation/American Heart Association Task Force on Practice Guidelines Developed in Collaboration With the International Society for Heart and Lung Transplantation. J Am Coll Cardiol. Apr 14; 2009 53(15):e1-e90. [PubMed: 19358937]

42. Dickstein K, Cohen-Solal A, Filippatos G, et al. ESC Guidelines for the diagnosis and treatment of acute and chronic heart failure 2008: the Task Force for the Diagnosis and Treatment of Acute and Chronic Heart Failure 2008 of the European Society of Cardiology. Developed in collaboration with the Heart Failure Association of the ESC (HFA) and endorsed by the European Society of Intensive Care Medicine (ESICM). European heart journal. Oct; 2008 29(19):2388-2442. [PubMed: 18799522]

43. Piepoli MF, Conraads V, Corra U, et al. Exercise training in heart failure: from theory to practice. A consensus document of the Heart Failure Association and the European Association for Cardiovascular Prevention and Rehabilitation. European journal of heart failure. Apr; 2011 13(4): 347-357. [PubMed: 21436360]

44. Bouchla A, Karatzanos E, Dimopoulos S, et al. The addition of strength training to aerobic interval training: effects on muscle strength and body composition in CHF patients. Journal of cardiopulmonary rehabilitation and prevention. Jan-Feb;2011 31(1):47-51. [PubMed: 20562711]

45. Teffaha D, Mourot L, Vernochet P, et al. Relevance of water gymnastics in rehabilitation programs in patients with chronic heart failure or coronary artery disease with normal left ventricular function. Journal of cardiac failure. Aug; 2011 17(8):676-683. [PubMed: 21807330]

46. Hambrecht R, Gielen S, Linke A, et al. Effects of exercise training on left ventricular function and peripheral resistance in patients with chronic heart failure: A randomized trial. JAMA : the journal of the American Medical Association. Jun 21; 2000 283(23):3095-3101. [PubMed: 10865304]

47. Belardinelli R, Georgiou D, Cianci G, Purcaro A. Randomized, controlled trial of long-term moderate exercise training in chronic heart failure: effects on functional capacity, quality of life, and clinical outcome. Circulation. Mar 9; 1999 99(9):1173-1182. [PubMed: 10069785] 
48. Savage PA, Shaw AO, Miller MS, et al. Effect of resistance training on physical disability in chronic heart failure. Medicine and science in sports and exercise. Aug; 2011 43(8):1379-1386. [PubMed: 21233772]

49. Dean AS, Libonati JR, Madonna D, Ratcliffe SJ, Margulies KB. Resistance training improves vasoreactivity in end-stage heart failure patients on inotropic support. The Journal of cardiovascular nursing. May-Jun;2011 26(3):218-223. [PubMed: 21263349]

50. Selig SE, Carey MF, Menzies DG, et al. Moderate-intensity resistance exercise training in patients with chronic heart failure improves strength, endurance, heart rate variability, and forearm blood flow. Journal of cardiac failure. Feb; 2004 10(1):21-30. [PubMed: 14966771] 


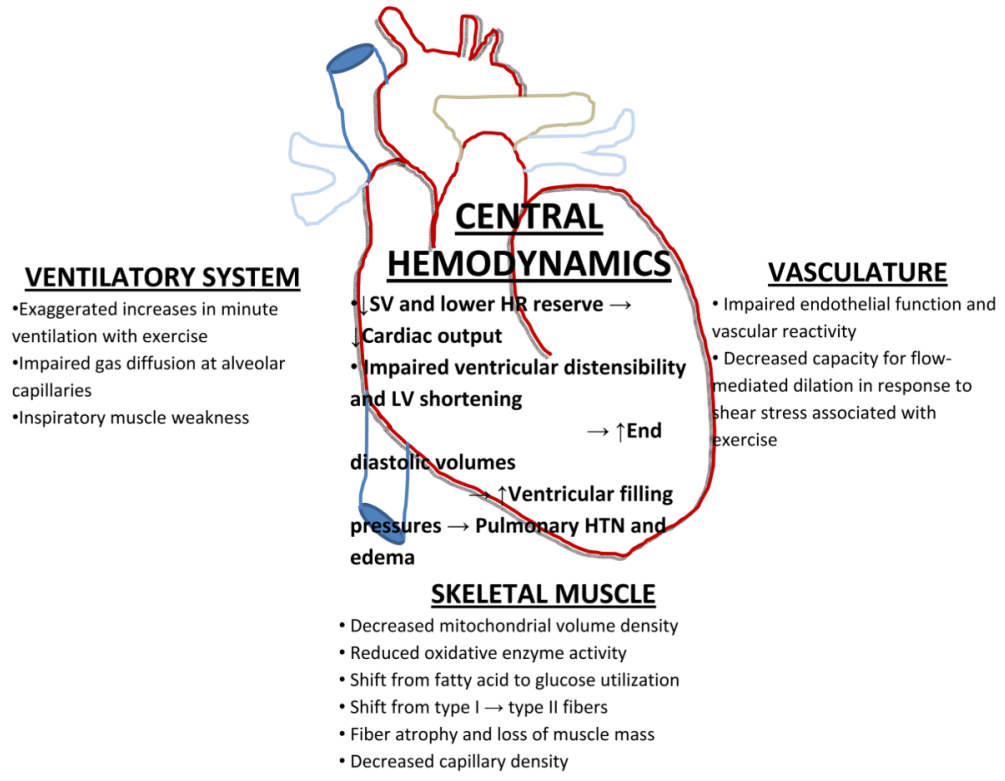

Figure 1.

Central and peripheral derangements in patients with heart failure contributing to impaired exercise tolerance. HR - heart rate; HTN - hypertension; LV - left ventricle; SV - stroke volume. 
Table 1

Impact of exercise training on peripheral derangements associated with heart failure.

FUNCTIONAL EFFECTS OF EXERCISE TRAINING IN HEART FAILURE

$\underline{\text { Skeletal Muscle }}$

- Increased mitochondrial volume density and ATP production rate

- $\quad$ Shift from type II back to type I fibers

- Increased capillary density

- Increased strength and endurance

- Improved sensitivity to adiponectin

Vasculature

- Improved endothelium-mediated vasodilation

- $\quad$ Favorable remodeling of conduit arteries

- Increased diameter of arterioles

- Decreased total peripheral resistance

Ventilatory System

- Increased $\mathrm{Pi}_{\max }$

- Enhanced efficiency of ventilation

- $\quad$ Reduced lactate levels during exercise

- Improved gas diffusion across alveolar capillaries 


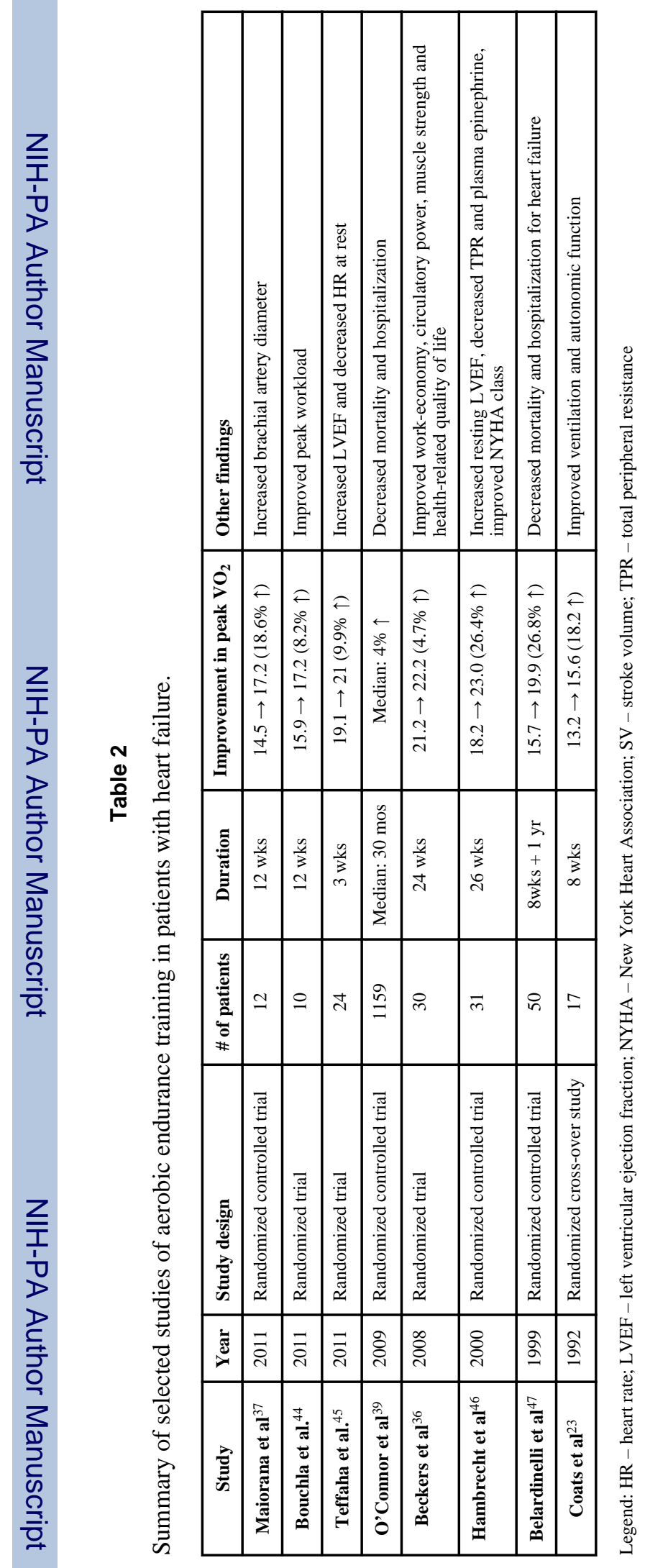




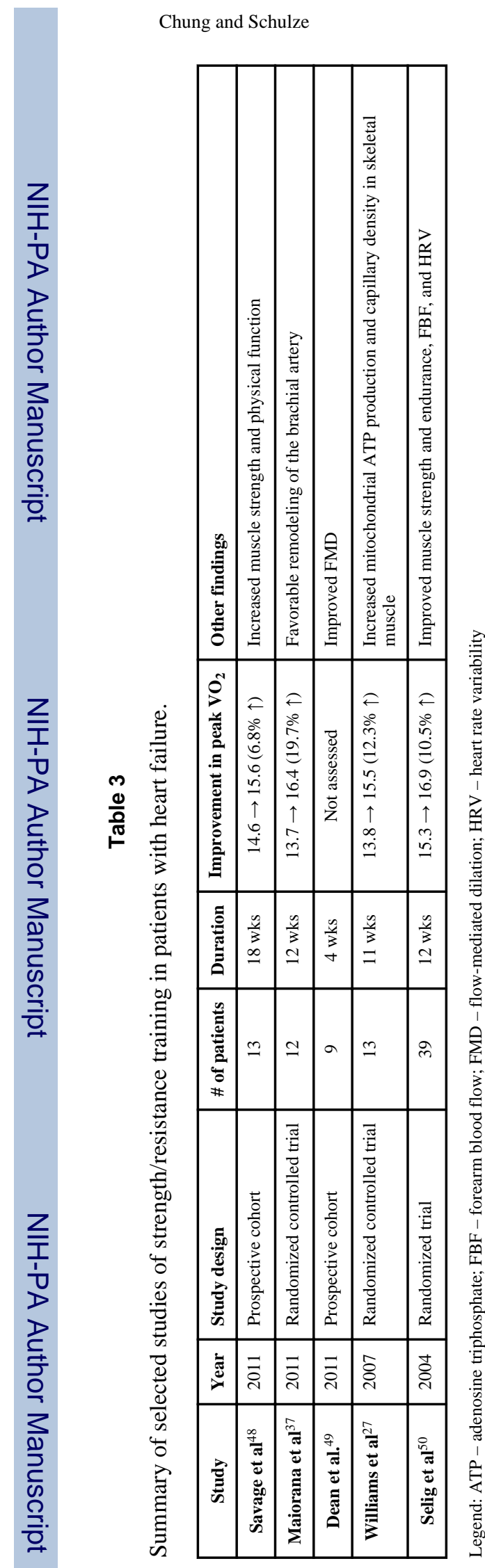

Page 13

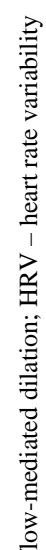

$\sum_{\text {I }}$ 